OPEN ACCESS

Edited by:

Álvaro Borges,

Statens Serum Institut (SSI), Denmark

Reviewed by:

Antonio Carlos Rosário Vallinoto, Federal University of Pará, Brazil

Masahiko Ito,

Hamamatsu University School

of Medicine, Japan

${ }^{*}$ Correspondence:

Maria Fernanda Rios Grassi

fernanda.grassi@fiocruz.br;

mfrgrassi@gmail.com

Specialty section:

This article was submitted to

Virology,

a section of the journal

Frontiers in Microbiology

Received: 23 November 2020 Accepted: 08 February 2021

Published: 26 February 2021

Citation:

Pereira FM, Ramos PIP, Lirio M, Mercês Atta A, Silva de Oliveira I,

Nascimento FCV, Silva MC,

Galvão-Castro B and Rios Grassi MF (2021) Evaluation of the Inflammatory

Cytokines and IL-10 Network in Individuals Co-infected With Human

T-Cell Lymphotropic Virus

and Hepatitis C Virus (HTLV/HCV).

Front. Microbiol. 12:632695.

doi: 10.3389/fmicb.2021.632695

\section{Evaluation of the Inflammatory Cytokines and IL-10 Network in Individuals Co-infected With Human T-Cell Lymphotropic Virus and Hepatitis C Virus (HTLV/HCV)}

Felicidade Mota Pereira',2, Pablo Ivan Pereira Ramos ${ }^{3}$, Monique Lirio', Ajax Mercês Atta ${ }^{4}$, Isabela Silva de Oliveira ${ }^{4}$, Fabio Carneiro Vosqui Nascimento ${ }^{5}$, Marcelo Costa Silva ${ }^{6}$, Bernardo Galvão-Castro ${ }^{7}$ and Maria Fernanda Rios Grassi ${ }^{1,7 *}$

\footnotetext{
'Laboratório Avançado de Saúde Pública, Fundação Oswaldo Cruz, Salvador, Brazil, ${ }^{2}$ Laboratório Central de Saúde Pública Prof. Gonçalo Moniz - Secretaria da Saúde do Estado da Bahia, Salvador, Brazil, ${ }^{3}$ Centro de Integração de Dados e Conhecimentos para Saúde - CIDACS, Fundação Oswaldo Cruz, Salvador, Brazil, ${ }^{4}$ Faculdade de Farmácia, Universidade Federal da Bahia, Salvador, Brazil, ${ }^{5}$ Secretaria Municipal de Saúde de Feira de Santana, Feira de Santana, Brazil,

${ }^{6}$ Secretaria da Saúde do Estado da Bahia, Salvador, Brazil, ${ }^{7}$ Escola Bahiana de Medicina e Saúde Pública, Salvador, Brazil
}

Background: Co-infection between the human T-cell lymphotropic virus (HTLV) and the hepatitis $\mathrm{C}$ virus $(\mathrm{HCV})$ can modify the natural history of HCV infection. The aim of this study was to describe the inflammatory cytokines and IL-10 network in patients co-infected with HTLV and HCV viruses in Bahia, Brazil.

Methods: Samples from $31 \mathrm{HTLV} / \mathrm{HCV}$ co-infected individuals and $27 \mathrm{HCV}$ monoinfected individuals were evaluated. IFN- $\gamma$, TNF- $\alpha$, IL-10, IL-8, and IL-1 cytokines were quantified by ELISA. Clinical, laboratory data were obtained from patient records. Serum levels of the cytokines were $\log _{10}$-transformed and data mining was performed using Z-score statistics and correlation analysis.

Results: Co-infected individuals presented a tendency toward higher production of INF$\gamma$ compared to the HCV monoinfected group. Regarding cytokine pairs, there was a positive correlation ( $P$-value $<0.05$ ) between IL-1 and IL-8 in the HTLV/HCV co-infected group and uninfected controls, and two correlations in the HCV mono-infected group IL-8 - IL10 and IL- INF- $\gamma$ - IL-10 pairs. There was no significant difference between the groups for the other parameters analyzed.

Conclusion: The results presented herein indicated that HTLV/HCV co-infection was associated with a trend in IFN- $\gamma$ production while HCV-infected individuals presented a positive correlation with both inflammatory cytokines (IL-8 and IFN- $\gamma$ ) and the regulatory cytokine IL-10.

Keywords: HTLV, HCV, co-infection, network, cytokines 


\section{INTRODUCTION}

Co-infection with Human T-Cell Leukemia Virus type 1 (HTLV1) or type 2 (HTLV-2) and the hepatitis $C$ virus (HCV) has been described in countries where both viruses are endemic (Nakashima et al., 1994), occurring mainly among drug users (de la Fuente et al., 2006; Zunt et al., 2006; Berini et al., 2007; Moreira et al., 2013). In Brazil, the prevalence of HTLV-1 varies according to the geographic region, in Bahia it is estimated that around $1 \%(\sim 130,000)$ people are infected by this virus (Pereira et al., 2019). The prevalence of HTLV infection reaches $5.3 \%$ in HCV carriers (Caterino-de-Araujo et al., 2018) and HTLV/HCV co-infection was identified in $1.5 \%$ in men who have sex with men (Catalan-Soares et al., 2014).

The clinical progression and immunological features of $\mathrm{HTLV} / \mathrm{HCV}$ co-infection remain poorly understood and vary in accordance with geographic region. Some studies have shown that HTLV-1/HCV co-infection has a synergistic effect on liver disease severity and lethality (Kishihara et al., 2001). In Japan, several reports suggest that the presence of HTLV1 negatively influences the natural course of HCV infection by reducing the cellular immune response against $\mathrm{HCV}$ and decreasing the cytotoxic action of T-lymphocytes against infected hepatocytes (Boschi-Pinto et al., 2000). In addition, it was reported that $\mathrm{HTLV} / \mathrm{HCV}$ co-infection worsened the progression of HCV infection to hepatocellular carcinoma (Kamihira et al., 1991; Tokunaga et al., 2014), and decreased the sustained virological response of interferon treatment against hepatitis C (Kishihara et al., 2001). In contrast, studies conducted in Brazil have shown that HTLV may contribute to the spontaneous clearance of $\mathrm{HCV}$ in co-infected individuals (Moreira et al., 2013; Le Marchand et al., 2015). Some co-infected individuals evaluated in Brazil present less hepatic fibrosis, higher $\mathrm{CD}^{+}{ }^{+} \mathrm{T}$-cell counts and lower alanine aminotransferase levels compared with $\mathrm{HCV}$-infected individuals alone (Bahia et al., 2011; Abad-Fernandez et al., 2015; Espindola et al., 2017).

While few studies have investigated cytokine profiles in the context of $\mathrm{HTLV} / \mathrm{HCV}$ co-infection, increased serum levels of IFN- $\gamma$ were reported in $\mathrm{HTLV} / \mathrm{HCV}$ co-infected patients compared to those with HCV alone (Silva et al., 2016). Moreover, individuals with triple $\mathrm{HTLV} / \mathrm{HIV} / \mathrm{HCV}$ infection present increased plasma levels of proinflammatory cytokines compared to others with HIV-HCV co-infection (Brites et al., 2018). The present study aimed to describe inflammatory and regulatory cytokine profiles in a group of $\mathrm{HTLV} / \mathrm{HCV}$ co-infected patients, and compare the obtained results with individuals infected with HCV alone.

\section{MATERIALS AND METHODS}

\section{Ethics Statement}

The Institutional Review Board (IRB) for Human Research at the Gonçalo Moniz Institute of the Oswaldo Cruz Foundation (Salvador, Bahia, Brazil) provided ethical approval to conduct this study (CAAE number 22478813.7.0000.0040).

\section{Study Population}

The study was conducted at the Central Laboratory of Public Health of the state of Bahia (LACEN/BA), from January 2014 to June 2016. All samples of individuals tested for HCV viral load quantification were sequentially selected. Individuals were included if they had been previously tested for HTLV serology (confirmed by Western blot) at LACEN. Subjects were distributed into two groups: Samples from $31 \mathrm{HTLV} / \mathrm{HCV}$ coinfected individuals and $27 \mathrm{HCV}$ monoinfected individuals were evaluated. Samples with a reagent result for HIV were excluded.

\section{Data Collection}

Socio demographic data and serological results for HTLV and HIV were obtained from the SMART LAB database that is the laboratory management system of LACEN-BA. Clinical information on inflammatory liver activity and degree of fibrosis [both evaluated by the METAVIR scale (Bedossa and Poynard, 1996)], presence of hepatic steatosis, ascites, hepatic encephalopathy, antiretroviral treatment (ART) to hepatitis $\mathrm{C}$, platelet count and prothrombin time were obtained from the patients' medical records. No clinical status of HTLV patients was available.

\section{HCV Viral Load and Genotyping}

Plasma samples were collected in tubes containing EDTAK3. $\mathrm{HCV}$ viral load was quantified using the Abbott RealTime HCV kit (ABBOTT Molecular Inc., Des Plaines, United States) and the determination of viral genotype was performed using the Abbott RealTime HCV Genotype II (ABBOTT Molecular Inc., Des Plaines, United States).

\section{Detection of Cytokines}

Cytokines were measured in the plasma of $\mathrm{HCV}$ - and $\mathrm{HTLV} / \mathrm{HCV}$-infected individuals. A control group consisting of 30 healthy individuals with non-reactive results for HTLV, HCV, $\mathrm{HIV}$, and demographic characteristics similar to those in the $\mathrm{HCV}$ and HTLV/HCV groups was selected from the sample bank of the Immunology Laboratory of the Pharmacy School of the Federal University of Bahia. The levels of INF- $\gamma$, TNF, and IL10, were measured using the Enzyme-linked Immunosorbent Assay kits (eBioscience, Bender, Vienna, Austria). The levels of IL-1 and IL-8 were measured using the Uncoated ELISA kits (Invitrogen, Bender, Vienna, Austria) in accordance with the manufacturer's instructions.

\section{Data Analysis}

Prism ${ }^{\circledR}$ Version 5.03 (GraphPad) was used for data analysis. The categorical variables (gender, inflammatory activity, degree of fibrosis, treatment, presence of steatosis, hepatic encephalopathy, as well as ascites) were presented as absolute and relative frequencies. The continuous variables (age, HCV viral load, platelet count, and prothrombin time) as central tendency and dispersion measures (mean, standard deviation, median and interquartile range, confidence interval). To compare proportions among categorical variables, the chi-square test $\left(\chi^{2}\right)$, ANOVA or Fisher's exact test were used. To compare continuous 
variables, the $t$-test for independent samples was used. The analyzes were bilateral (two-tailed), and a value of $P \leq 0.05$ was considered statistically significant.

\section{Data Mining of Cytokine Profiles}

Serum levels of the cytokines IFN- $\gamma$, TNF- $\alpha$, IL-10, IL-8, and IL-1 of the evaluated groups were $\log _{10}$-transformed prior to data mining using Z-score statistics and correlation analysis. In order to avoid log evaluation errors, the values equal to zero were replaced by the detection limit of the instrument according to the manufacturer. Conversely, the values exceeding the upper limit were replaced by the upper limit of detection. Deviations from the mean were calculated as Z-scores aggregated across groups using the scale function in R 3.2.2 (R Core Team, 2018), allowing to disclose trend changes in cytokine profiles. Additionally, correlation analysis was performed to infer withingroup associations between cytokine-cytokine pairs.

The $\mathrm{R}$ package qpgraph v. 2.10.2 (Castelo and Roverato, 2006) was used to calculate Pearson's correlation statistic and corresponding $P$-values.

In order to disclose a network from these associations, the package igraph v. 1.2.2 (Csardi and Nepusz, 2006) was used based on a nominal correlation $P$-value threshold of $<0.05$ to establish an edge between cytokine nodes, with self-loops removed for clarity.

\section{RESULTS}

A total of 58 individuals (31 HTLV/HCV and $27 \mathrm{HCV}$ ) and 30 uninfected controls were included. No statistically significant differences were seen between individuals with $\mathrm{HTLV} / \mathrm{HCV}$ co-infection, HCV-infected patients and controls with respect median age and sex. Most co-infected individuals resided in the municipality of Salvador $(P<0.0001)$ (Table 1$)$.

Regarding clinical data, the frequencies of steatosis, ascites and neurological findings suggestive of hepatic encephalopathy were similar between the HTLV/HCV and HCV groups. No statistically significant differences were found between these groups in the proportion of non-responders to HCV ART, yet this proportion was higher in HCV-infected individuals (44\%)

TABLE 1 | Demographic characteristics of HTLV/ HCV-, HCV-infected patients and controls.

\begin{tabular}{|c|c|c|c|c|}
\hline Variable & $\begin{array}{c}\text { HTLV/HCV } \\
N=31\end{array}$ & $\begin{array}{c}\text { HCV } \\
N=27\end{array}$ & $\begin{array}{c}\text { CONTROL } \\
N=30\end{array}$ & $P$-value \\
\hline Age (years) & $61(55-68)$ & $63(56-69)$ & $61(56-67)$ & 0.6598 \\
\hline \multicolumn{5}{|l|}{ Sex, $n(\%)$} \\
\hline Male & $17(55)$ & $14(52)$ & $15(50)$ & 0.9297 \\
\hline Female & $14(45)$ & $13(48)$ & $15(50)$ & \\
\hline City of origin, $N(\%)$ & & & & $<0.0001$ \\
\hline Salvador & $21(68)$ & $11(41)$ & $30(100)$ & \\
\hline Other & 10 (32) & $16(59)$ & 0 & \\
\hline
\end{tabular}

TABLE 2 | Clinical and histopathological findings of HTLV/HCV-co-infected and HCV-infected individuals.

\begin{tabular}{|c|c|c|c|c|c|}
\hline \multirow[t]{2}{*}{ Variable } & \multicolumn{2}{|c|}{ HTLV/HCV } & \multicolumn{2}{|c|}{ HCV } & \multirow[t]{2}{*}{$P$-value } \\
\hline & $\mathbf{N}$ & $n(\%)$ & $\mathbf{N}$ & $n(\%)$ & \\
\hline HCV ART (non-responders) & 17 & $6(35)$ & 16 & $7(44)$ & 0.72 \\
\hline Liver inflammatory activity (A2-A3) ${ }^{*}$ & 20 & $7(35)$ & 14 & $6(43)$ & 0.73 \\
\hline Liver fibrosis (F3-F4) $)^{\star}$ & 21 & $9(43)$ & 14 & $9(64)$ & 0.31 \\
\hline
\end{tabular}

*METAVIR scale; comparisons made using Fisher's exact test.

compared to HTLV/HCV (35\%) $(P=0.72)$ (Table 2). Liver biopsy results were available from 21 out of $31 \mathrm{HTLV} / \mathrm{HCV}$ coinfected individuals and 14 out of $27 \mathrm{HCV}$-infected individuals. Moderate/severe inflammatory activity (A2-A3) was observed in $35 \%(7 / 20)$ of the HTLV/HCV individuals and $43 \%(6 / 14)$ of $\mathrm{HCV}$ patients. The frequency of advanced fibrosis (F3-F4) was slightly lower in the HTLV/HCV $(43 \%, 9 / 21)$ group compared to $\mathrm{HCV}$-infected $(64 \%, 9 / 14)$ individuals. Liver cirrhosis was identified in two individuals in each group.

No significant differences were observed in mean $\mathrm{HCV}$ viral load between the HTLV/HCV $(5.3 \pm 1.9 \mathrm{log})$ and HCV $(4.9 \pm 1.5 \mathrm{log})$ groups $(P=0.428)$. Viral load was more frequently undetectable in the HTLV/HCV group $(26 \%, 8 / 31)$ compared to $\mathrm{HCV}(7.4 \%, 2 / 27)(P=0.08)$. Mean platelet count and prothrombin time were similar between the groups (Figure 1).

Hepatitis C virus genotype 1 was identified in $74.2 \%(23 / 31)$ and $85.2 \%(23 / 27)$ of the $\mathrm{HTLV} / \mathrm{HCV}$ and HCV groups, respectively, while genotype 2 was found in $3.2 \%(1 / 31)$ of the $\mathrm{HTLV} / \mathrm{HCV}$ group. Genotype 3 was detected in $9.7 \%(3 / 31)$ and $7.4 \%(2 / 27)$ of individuals with $\mathrm{HTLV} / \mathrm{HCV}$ and $\mathrm{HCV}$ infection, respectively.

With respect to cytokine levels, both $\mathrm{HTLV} / \mathrm{HCV}$ and HCV groups presented lower levels of TNF, IL-10, and IL-8 compared to uninfected controls ( $P$-value $<0.001)$ (Figure 2A). Then, a Z-score analysis was performed to identify subtler deviations in cytokine levels across all groups. A trend toward higher IFN- $\gamma$ production was observed in the HTLV/HCV group compared to HCV (Figure 2B), albeit this difference was not supported by statistical significance. With respect to cytokine pairs (Figure 2C), statistically significant associations were identified between IL- 1 and IL- 8 in the uninfected control group and the HTLV/HCV co-infected group. Two statistically significant associations between IL-8/IL-10 and IFN- $\gamma /$ IL-10 were found in the HCV group (Figure 2).

\section{DISCUSSION}

The present study aimed to evaluate aspects of HTLV/HCV co-infection in comparison to $\mathrm{HCV}$ infection alone. We evaluated inflammatory (INF- $\gamma$, TNF, IL-1, and IL-8) and regulatory (IL-10) cytokine networks in HTLV/HCV-co-infected and $\mathrm{HCV}$-infected individuals. Cytokine production was found to be similar between these groups, yet TNF, IL-8, and TNF levels were lower than in uninfected controls. Similar results have been described in other studies reporting on 


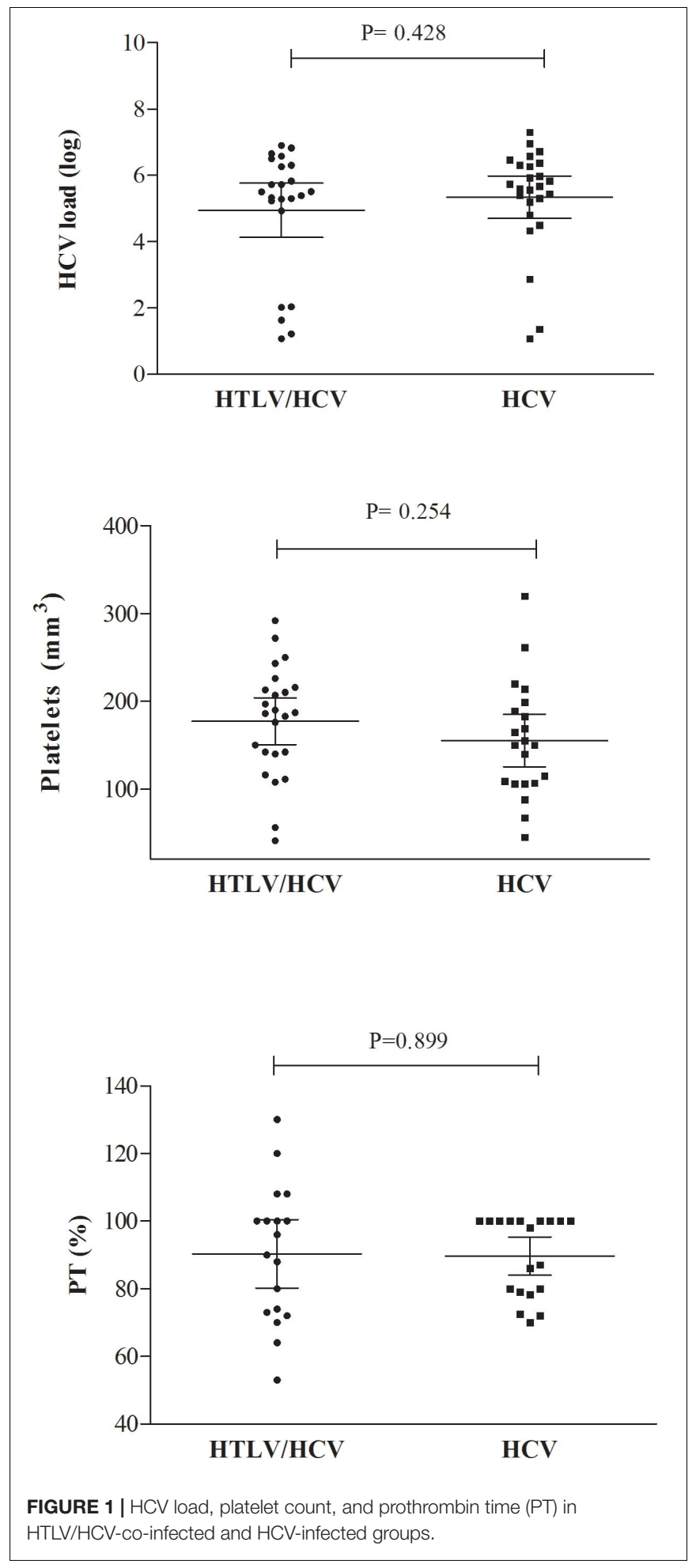

HCV infection, as HTLV co-infection was not found to influence cytokine levels (Abad-Fernandez et al., 2015; Silva et al., 2016). However, the present evaluation of trend changes in cytokine profile between infected and co-infected groups identified higher IFN- $\gamma$ production in the HTLV/HCV group compared to HCV. Indeed, HTLV-1 infection has been strongly associated with higher inflammatory cytokine production, especially INF- $\gamma$ (Carvalho et al., 2001), which could explain the relatively increased production of this cytokine in HTLV/HCVinfected individuals.

The evaluation of cytokine networks revealed a similar profile between HTLV/HCV-co-infected individuals and uninfected controls, with a positive association identified between IL-1 and IL-8. By contrast, a positive correlation between the IL-8/IL-10 and INF- $\gamma /$ IL-10 pairs was identified in the HCV-infected group. IL-8 levels have been reported to be inversely correlated with liver disease activity, since reduced concentrations of this cytokine are observed following effective antiviral treatment (Alhetheel et al., 2016). IFN- $\gamma$ is directly associated with an effective cytotoxic response to $\mathrm{HCV}$ and to the control of virus replication (Thimme et al., 2006). On the other hand, high levels of IL10 were shown to lead to an impairment in cytotoxic response, decreased inflammatory response and progression to liver fibrosis (Nelson et al., 2000; Mege et al., 2006; Aroucha et al., 2013; de Souza-Cruz et al., 2016).

The suppressor effect of IL-10 could be responsible for the lower cytotoxic response and higher HCV viral loads seen inpatients infected with $\mathrm{HCV}$ alone. In fact, despite a lack of statistical significance, $26 \%$ of HTLV/HCV-co-infected individuals had undetectable viral load versus just $7.4 \%$ in the HCV group $(P=0.08)$. Moreover, more $\mathrm{HCV}$-infected patients were non-responders to the treatment, with high inflammatory liver activity and advanced liver fibrosis. In Brazil, some studies have suggested that HTLV co-infection may have a positive effect on spontaneous HCV clearance (Alves et al., 2018), which occurs equally in patients triple infected with HTLV, HCV, and HIV-1 (Bahia et al., 2011; Moreira et al., 2013; Le Marchand et al., 2015). However, a study conducted in Japan reported that HTLV decreased the response to the treatment with IFN- $\alpha$ and reduced the clearance of HCV (Kishihara et al., 2001). These conflicting results may be due to differences in the therapeutic protocols used in Japan and Brazil that combines antivirals with the IFN- $\alpha$.

In addition, differences in the viral genotype may also influence the response to the treatment. In the present study, $\mathrm{HCV}$ genotype 1 was the most frequent in both $\mathrm{HCV}$ and HTLV/HCV co-infected groups. Similar results were reported in other studies conducted in Salvador, Bahia, and Rio de Janeiro (Silva et al., 2016; Espindola et al., 2017). This genotype is commonly associated with failure to antiviral treatment (Simmonds et al., 1996, 2005). However, most patients in the present study were responsive to treatment and had few advanced fibrosis and high inflammatory activity.

The present study is limited by its study design that does not allow to make any causal and temporal association. The majority of included patients were under ART for HCV infection and had a partial control of the viremia. It is possible that the cytokine network between inflammatory/regulatory cytokines of naïve patients was modified by therapy. In addition, a HTLV single-infected patients group for comparison purposes was not included, and the impact of HCV on HTLV infection could not be assessed. 

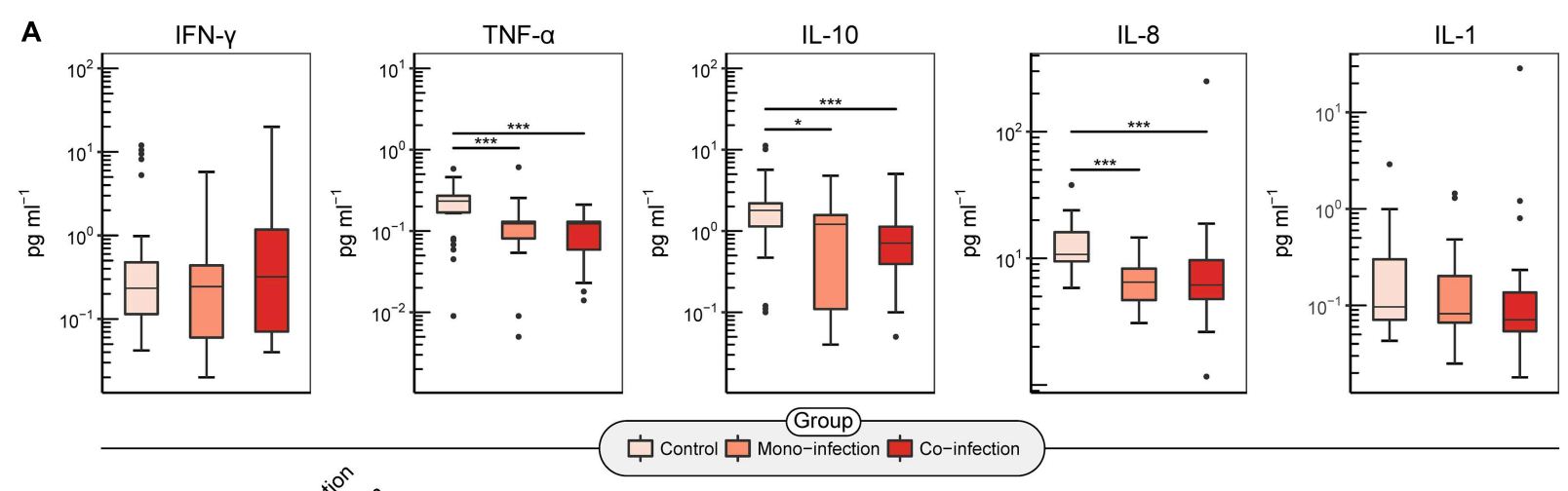

B

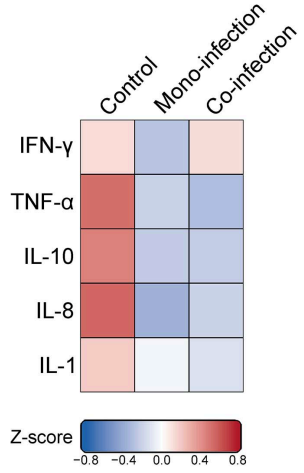

C Control

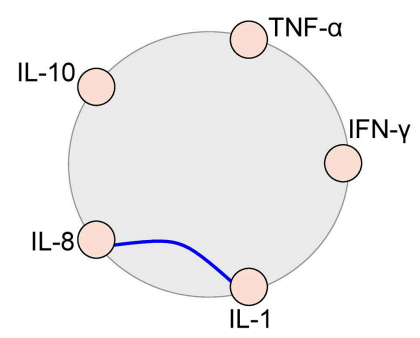

Mono-infection

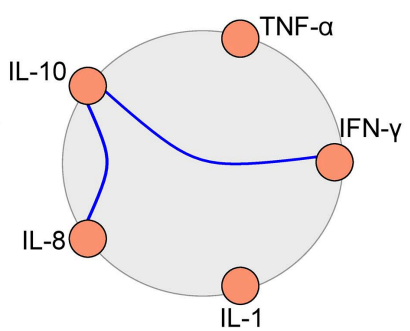

Co-infection

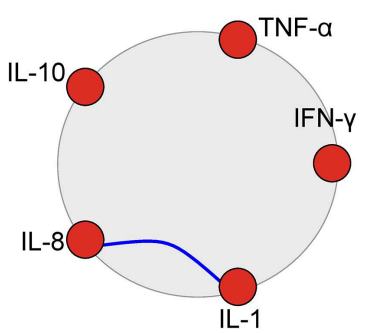

FIGURE 2 | Analysis of cytokine expression among the compared groups. (A) Boxplots of serum levels (pg/mL) of log10-transformed IFN- $\gamma$, TNF, IL-10, IL-8, and IL-1 cytokines. ${ }^{*} p<0.05,{ }^{\star \star \star} p<0.001$ (Kruskal-Wallis with Dunn's post-test and Holm's correction for $P$-value adjustment). (B) Heatmap generated from Z-scores calculated across groups illustrates differences in cytokine profiles among the compared groups. (C) Cytokine networks constructed using Pearson's correlation coefficient depict pairwise relationships between cytokine expression levels. Blue-colored links between nodes represent statistically significant positive correlations.

\section{CONCLUSION}

In conclusion, the results presented herein indicated that HTLV/HCV co-infection was associated with a trend to IFN- $\gamma$ production while HCV-infected individuals presented a positive correlation between both inflammatory cytokines (IL-8 and IFN$\gamma)$ and the regulatory cytokine IL-10. The trend of higher IFN- $\gamma$ levels observed in HTLV/HCV co-infected individuals may be related to the partial control of the viremia in these individuals, with a greater proportion of undetectable viral load and clinical responders to the treatment.

\section{DATA AVAILABILITY STATEMENT}

The raw data supporting the conclusions of this article will be made available by the authors, without undue reservation.

\section{ETHICS STATEMENT}

The studies involving human participants were reviewed and approved by the Institutional Research Board of Fiocruz. Written informed consent for participation was not required for this study in accordance with the national legislation and the institutional requirements.

\section{AUTHOR CONTRIBUTIONS}

FP, PR, AM, BG-C, and MG: study conception and design. FP, PR, ML, IS, FN, MS, and MG: acquisition of data. FP, PR, ML, AM, IS, FN, MS, BG-C, and MG: analysis and interpretation of data. FP, PR, BG-C, and MG: drafting of the manuscript and critical revision. All authors have read and approved the final version of the manuscript.

\section{FUNDING}

This work was supported by the Coordination of Superior Level Staff Improvement - Brazil (CAPES) - Finance Code 001 and National Foundation for the Development of Private Higher Education (FUNADESP), grants 9600140, and 9600141. MG and BG-C are research fellows of $\mathrm{CNPq}$ (process nos. 304811/2017-3s and 311054/2014-5, respectively).

\section{ACKNOWLEDGMENTS}

We thank Andris K. Walter for providing English language revision and manuscript copyediting assistance. 


\section{REFERENCES}

Abad-Fernandez, M., Moreno, A., Dronda, F., del Campo, S., Quereda, C., Casado, J. L., et al. (2015). Delayed liver fibrosis in HTLV-2-infected patients co-infected with HIV-1 and hepatitis $\mathrm{C}$ virus with suppressive antiretroviral therapy. AIDS 29, 401-409. doi: 10.1097/qad.0000000000000555

Alhetheel, A., Albarrag, A., Shakoor, Z., Alswat, K., Abdo, A., and Al-Hamoudi, W. (2016). Assessment of pro-inflammatory cytokines in sera of patients with hepatitis C virus infection before and after anti-viral therapy. J. Infect. Dev. Ctries. 10, 1093-1098. doi: 10.3855/jidc.7595

Alves, F. A., Campos, K. R., Lemos, M. F., Moreira, R. C., and Caterino-de-Araujo, A. (2018). Hepatitis C viral load in HCV-monoinfected and HCV/HIV- 1-, HCV/HTLV-1/- 2-, and HCV/HIV/HTLV-1/-2-co-infected patients from Sao Paulo, Brazil. Braz. J. Infect. Dis. 22, 123-128. doi: 10.1016/j.bjid.2018.03.002

Aroucha, D. C., do Carmo, R. F., Moura, P., Silva, J. L., Vasconcelos, L. R., Cavalcanti, M. S., et al. (2013). High tumor necrosis factor-alpha/interleukin10 ratio is associated with hepatocellular carcinoma in patients with chronic hepatitis C. Cytokine 62, 421-425. doi: 10.1016/j.cyto.2013.03.024

Bahia, F., Novais, V., Evans, J., Le Marchand, C., Netto, E., Page, K., et al. (2011). The impact of human T-cell lymphotropic virus I infection on clinical and immunologic outcomes in patients coinfected with HIV and hepatitis $\mathrm{C}$ virus. J. Acquir. Immune. Defic. Syndr. 57(Suppl. 3), S202-S207.

Bedossa, P., and Poynard, T. (1996). An algorithm for the grading of activity in chronic hepatitis C. The METAVIR cooperative study group. Hepatology 24, 289-293. doi: 10.1002/hep.510240201

Berini, C. A., Pando, M. A., Bautista, C. T., Eirin, M. E., Martinez-Peralta, L., Weissenbacher, M., et al. (2007). HTLV-1/2 among high-risk groups in Argentina: molecular diagnosis and prevalence of different sexual transmitted infections. J. Med. Virol. 79, 1914-1920. doi: 10.1002/jmv.21036

Boschi-Pinto, C., Stuver, S., Okayama, A., Trichopoulos, D., Orav, E. J., Tsubouchi, H., et al. (2000). A follow-up study of morbidity and mortality associated with hepatitis $C$ virus infection and its interaction with human $T$ lymphotropic virus type I in Miyazaki, Japan. J. Infect. Dis. 181, 35-41. doi: 10.1086/315177

Brites, C., Abrahao, M., Bozza, P., Netto, E. M., Lyra, A., and Bahia, F. (2018). Infection by HTLV-1 is associated with high levels of proinflammatory cytokines in HIV-HCV-coinfected patients. J. Acquir. Immune Defic. Syndr. 77, 230-234. doi: 10.1097/qai.0000000000001576

Carvalho, E. M., Bacellar, O., Porto, A. F., Braga, S., Galvao-Castro, B., and Neva, F. (2001). Cytokine profile and immunomodulation in asymptomatic human T-lymphotropic virus type 1-infected blood donors. J. Acquir. Immune Defic. Syndr. 27, 1-6. doi: 10.1097/00126334-200105010-00001

Castelo, R., and Roverato, A. (2006). A robust procedure for Gaussian graphical model search from microarray data with p larger than n. J. Mach. Learn. Res. 7, 2621-2650.

Catalan-Soares, B., Georg, I., Lampe, E., Lewis, L., Morgado, M. G., Nicol, A. F., et al. (2014). HIV-1, HBV, HCV, HTLV, HPV-16/18, and Treponema pallidum infections in a sample of Brazilian men who have sex with men. PLoS One 9:e102676. doi: 10.1371/journal.pone.0102676

Caterino-de-Araujo, A., Alves, F. A., Campos, K. R., Lemos, M. F., and Moreira, R. C. (2018). Making the invisible visible: searching for human T-cell lymphotropic virus types 1 and 2 (HTLV-1 and HTLV-2) in Brazilian patients with viral hepatitis B and C. Mem. Inst. Oswaldo Cruz 113, 130-134. doi: 10.1590/0074-02760170307

Csardi, G., and Nepusz, T. (2006). The igraph software package for complex network research. InterJ. Complex Syst. 1695, 1-9.

de la Fuente, L., Toro, C., Soriano, V., Brugal, M. T., Vallejo, F., Barrio, G., et al. (2006). HTLV infection among young injection and non-injection heroin users in Spain: prevalence and correlates. J. Clin. Virol. 35, 244-249. doi: 10.1016/j. jcv.2005.06.006

de Souza-Cruz, S., Victoria, M. B., Tarrago, A. M., da Costa, A. G., Pimentel, J. P., Pires, E. F., et al. (2016). Liver and blood cytokine microenvironment in $\mathrm{HCV}$ patients is associated to liver fibrosis score: a proinflammatory cytokine ensemble orchestrated by TNF and tuned by IL-10. BMC Microbiol. 16:3. doi: 10.1186/s12866-015-0610-6

Espindola, O. M., Vizzoni, A. G., Lampe, E., Andrada-Serpa, M. J., Araujo, A. Q., and Leite, A. C. (2017). Hepatitis C virus and human T-cell lymphotropic virus type 1 co-infection: impact on liver disease, virological markers, and neurological outcomes. Int. J. Infect. Dis. 57, 116-122. doi: 10.1016/j.ijid.2017. 01.037

Kamihira, S., Momita, S., Ikeda, S., Yamada, Y., Sohda, H., Atogami, S., et al. (1991). Cohort study of hepatotropic virus and human T lymphotropic virus type-I infections in an area endemic for adult $\mathrm{T}$ cell leukemia. Jpn. J. Med. 30, 492-497. doi: 10.2169/internalmedicine1962.30.492

Kishihara, Y., Furusyo, N., Kashiwagi, K., Mitsutake, A., Kashiwagi, S., and Hayashi, J. (2001). Human T lymphotropic virus type 1 infection influences hepatitis C virus clearance. J. Infect. Dis. 184, 1114-1119. doi: 10.1086/323890

Le Marchand, C., Bahia, F., Page, K., and Brites, C. (2015). Hepatitis C virus infection and spontaneous clearance in HTLV-1 and HIV co-infected patients in Salvador, Bahia, Brazil. Braz. J. Infect. Dis. 19, 486-491. doi: 10.1016/j.bjid. 2015.06.007

Mege, J. L., Meghari, S., Honstettre, A., Capo, C., and Raoult, D. (2006). The two faces of interleukin 10 in human infectious diseases. Lancet Infect. Dis. 6, 557-569. doi: 10.1016/s1473-3099(06)70577-1

Moreira, M., Ramos, A., Netto, E. M., and Brites, C. (2013). Characteristics of coinfections by HCV and HBV among Brazilian patients infected by HIV-1 and/or HTLV-1. Braz. J. Infect. Dis. 17, 661-666. doi: 10.1016/j.bjid.2013.04.009

Nakashima, K., Hayashi, J., Hirata, M., Kashiwagi, S., and Eda, F. (1994). Hepatitis C virus infection on Iki Island, Japan, an area endemic for human T-lymphotropic virus type-I. A preliminary study in patients at clinics or hospitals. J. Epidemiol. 4, 17-23. doi: 10.2188/jea.4.17

Nelson, D. R., Lauwers, G. Y., Lau, J. Y., and Davis, G. L. (2000). Interleukin 10 treatment reduces fibrosis in patients with chronic hepatitis C: a pilot trial of interferon nonresponders. Gastroenterology 118, 655-660. doi: 10.1016/s00165085(00)70134-x

Pereira, F. M., de Almeida, M., Santos, F. L. N., Carreiro, R. P., Regis-Silva, C. G. Galvao-Castro, B., et al. (2019). Evidence of new endemic clusters of human T-Cell Leukemia Virus (HTLV) infection in Bahia. Front. Microbiol. 10:1002. doi: $10.3389 /$ fmicb.2019.01002

R Core Team (2018). R: A Language and Environment for Statistical Computing. Vienna: R Foundation for Statistical Computing.

Silva, M. C., Silva, C. A., Machado, G. U., Atta, A., Freire, S. M., Carvalho, E., et al. (2016). HCV/HTLV coinfection: does HTLV-1 interfere in the natural history of HCV-related diseases? J. Med. Virol. 88, 1967-1972.

Simmonds, P., Bukh, J., Combet, C., Deleage, G., Enomoto, N., Feinstone, S., et al. (2005). Consensus proposals for a unified system of nomenclature of hepatitis $\mathrm{C}$ virus genotypes. Hepatology. 42, 962-973.

Simmonds, P., Mellor, J., Sakuldamrongpanich, T., Nuchaprayoon, C., Tanprasert, S., Holmes, E. C., et al. (1996). Evolutionary analysis of variants of hepatitis $\mathrm{C}$ virus found in South-East Asia: comparison with classifications based upon sequence similarity. J. Gen. Virol. 77(Pt 12), 3013-3024.

Thimme, R., Lohmann, V., and Weber, F. (2006). A target on the move: innate and adaptive immune escape strategies of hepatitis C virus. Antiviral Res. 69, 129-141.

Tokunaga, M., Uto, H., Oda, K., Tokunaga, M., Mawatari, S., Kumagai, K., et al. (2014). Influence of human T-lymphotropic virus type 1 coinfection on the development of hepatocellular carcinoma in patients with hepatitis $C$ virus infection. J. Gastroenterol. 49, 1567-1577.

Zunt, J. R., Tapia, K., Thiede, H., Lee, R., and Hagan, H. (2006). HTLV-2 infection in injection drug users in King County, Washington. Scand. J. Infect. Dis. 38, 654-663.

Conflict of Interest: The authors declare that the research was conducted in the absence of any commercial or financial relationships that could be construed as a potential conflict of interest.

Copyright ( 2021 Pereira, Ramos, Lirio, Mercês Atta, Silva de Oliveira, Nascimento, Silva, Galvão-Castro and Rios Grassi. This is an open-access article distributed under the terms of the Creative Commons Attribution License (CC BY). The use, distribution or reproduction in other forums is permitted, provided the original author(s) and the copyright owner(s) are credited and that the original publication in this journal is cited, in accordance with accepted academic practice. No use, distribution or reproduction is permitted which does not comply with these terms. 